\title{
Narrativas sobre o golpe no Brasil: acontecimento, jornalismo e disputas de sentido
}

\author{
Carlos Alberto de Carvalho
}

Universidade Federal de Minas Gerais, Belo Horizonte, Minas Gerais, Brasil

\section{Resumo}

Ancorados em acontecimentos políticos brasileiros recentes - o impeachment de Dilma Rousseff e os processos judiciais que levaram à condenação e prisão do ex-presidente Luiz Inácio Lula da Silva - refletimos sobre disputas de sentido e jogos de poder que envolvem os gestos de narrar jornalisticamente os acontecimentos. Metodologicamente, analisamos notícias recolhidas dos sites $U o l$ e Jornal GGN, adotando como procedimento entrecruzamentos possíveis entre narrativas e acontecimentos. Da análise emergem disputas de sentido na definição dos acontecimentos políticos que contrapõem a noção de golpe contra a democracia à de ações políticas e judiciais pautadas por princípios constitucionais.

\section{Palavras-chave}

Jornalismo. Acontecimento. Narrativa.

\section{Introdução}

Os acontecimentos políticos no Brasil a partir da reeleição de Dilma Rousseff, do Partido dos Trabalhadores (PT), em 2014, que culminaram no polêmico impeachment que a retirou da presidência em 2016, colocaram em cena como atores sociais proeminentes a mídia, a Polícia Federal, o Ministério Público e o Poder Judiciário, no que tem sido considerada uma orquestração de ações entre eles, ou ao menos entre partes deles constituintes. Em sociedades tidas como democráticas, uma das pressuposições é que todas as instituições atuem de forma autônoma, responsável e agindo motivadas exclusivamente segundo preceitos éticos e legais estabelecidos como válidos, em sua aplicação, ao conjunto da sociedade, sem distinções. Consequentemente, à imprensa pressupõe-se a defesa da pluralidade de pontos de vista, rigorosa checagem de informações, vigilância sobre os poderes formais e outras premissas que, embora sempre repetidas, soam mais como mitologia do que propriamente condições verificáveis, ao longo da história e para um 
conjunto heterogêneo de sociedades e suas formas de produção e circulação jornalísticas. Aos poderes policiais e ligados à aplicação da lei, também são atribuídas ações que se pautariam acima de interesses econômicos, políticos e ideológicos que, no entanto, em momentos críticos se desfazem.

Articulando os conceitos de acontecimento e narrativa, naquilo que ambos apresentam como potencialidades heurísticas a partir dos seus mútuos entrecruzamentos, tal como encontramos, por exemplo, na obra Tempo e narrativa, de Paul Ricoeur (1994, 1995, 1997), nos debruçamos neste artigo sobre os acontecimentos políticos brasileiros recentes buscando compreender os modos como as disputas de sentido e os jogos de poder envolvem narrativas que conflitam acerca dos significados dos eventos em curso. Como ponto de partida, nos orientamos pela proposição de Pierre Nora (1983, 1984) de que não haveria, modernamente, acontecimento sem a mídia.

Em relação aos acontecimentos que levaram ao impeachment da presidenta Dilma Rousseff, uma das principais discussões na sociedade brasileira foi se ele constituiu ou não um golpe, no sentido de interrupção de um mandato presidencial a partir de alegações jurídicas frágeis. No caso, a acusação de "pedaladas fiscais", que consistiriam no atraso de repasses de recursos do Tesouro Nacional a instituições bancárias, com o intuito de apresentar melhores resultados econômicos governamentais, elevando artificialmente superávits primários ou camuflando déficits orçamentários ${ }^{1}$. Tal prática sempre foi expediente adotado por governos anteriores, assim como é recorrente em administrações estaduais e municipais, sem punições a quem as tenha executado, incluindo os ex-presidentes Fernando Henrique Cardoso e Luiz Inácio Lula da Silva.

Não bastassem as dúvidas em torno das "pedaladas fiscais" como motivos juridicamente válidos para abrir o processo de impeachment contra Dilma Rousseff, a iniciativa parlamentar de levar adiante os procedimentos ocorreu a partir da recusa do PT em votar favoravelmente ao arquivamento de denúncia contra o então presidente da Câmara dos Deputados, Eduardo Cunha, envolvido em uma série de acusações de corrupção e que, 
após a derrubada da presidenta Dilma Rousseff, na qual teve papel decisivo, acabou condenado e preso. Por retaliação ao partido da presidenta, Eduardo Cunha acatou o processo de impeachment, que acabou aprovado pela Câmara e pelo Senado, em meio a polêmicas políticas e jurídicas. É importante registrar que diversos deputados e senadores que votaram pela saída de Dilma Rousseff, a quem ainda foram atribuídas supostas atividades ilícitas, são investigados por corrupção, cujo combate foi uma das armas utilizadas para mobilização contra a presidenta.

O impedimento de Dilma Rousseff não constitui o único elemento político necessário para a compreensão das razões que levam às disputas de sentido sobre o acontecimento impeachment, se golpe ou decisão em consonância com os princípios legais brasileiros. Os acontecimentos políticos no Brasil vieram na esteira de dificuldades econômicas, que em muito contribuíram para deteriorar a imagem de Dilma Rousseff, cujo partido, o PT, desde a primeira eleição de Lula, passou a ser alvo frequente de acusações de corrupção, não necessariamente comprovadas, mas que têm resultado na prisão de diversos membros desse partido, enquanto acusações de corrupção contra políticos de denominações que fazem oposição ao PT, nomeadamente do Partido da Social Democracia Brasileira (PSDB), mas não só, dificilmente resultam em punições legais, ainda quando há fortes indícios comprobatórios de atos ilícitos, como malas de dinheiro e documentos comprovando desvios orçamentários de obras públicas.

Nesse cenário, atuam setores da imprensa, da Polícia Federal, do Ministério Público e do Poder Judiciário, em ações como conduções coercitivas de pessoas que não haviam anteriormente sido convocadas a depor e se recusado a fazê-lo; vazamentos para a imprensa de conversas de telefonemas gravados sem conhecimento dos interlocutores ou produzidas com finalidades investigativas; acusações formais contra políticos a partir de convicções e suposições, sem as necessárias provas que consubstanciassem crimes efetivos; procuradores do Ministério Público e juízes emitindo opiniões, na imprensa, sobre casos sob sua responsabilidade, o que é vetado; dentre uma série de outras atitudes controversas quanto à manutenção de equilíbrio e justiça.

Nas ações de vazamento, a mais polêmica foi a divulgação de conversa telefônica, feita pelo juiz de primeira instância, Sergio Moro, nomeado em 2019 como ministro da Justiça, mantida entre a presidenta Dilma Rousseff e o ex-presidente Lula, quando da nomeação deste como ministro da Casa Civil, no auge da efervescência política que precedeu 
o impeachment². A Constituição Brasileira proíbe a interceptação e divulgação de conversas de presidentes, exceto quando autorizadas pelo Supremo Tribunal Federal (STF), o que não havia ocorrido. Sergio Moro foi o responsável pela denominada Operação Lava Jato, que investiga corrupção na Petrobras, envolvendo políticos e empresários. Embora as denúncias de corrupção atinjam políticos de todos os partidos brasileiros, foi especialmente sobre o PT que recaíram as principais ações da justiça, em especial aquelas sob responsabilidade de Sergio Moro, acusado por juristas de variados matizes conceituais de agir seletivamente, protegendo políticos de oposição ao PT e sendo rigoroso com quadros deste partido.

A Operação Lava Jato constituiu um dos elementos fundamentais para o desenrolar de algumas ações políticas que culminaram no impeachment, tais como a condução coercitiva do ex-presidente Lula, a divulgação de conversas dele e de familiares, apontadas por setores sociais brasileiros como realizadas sempre no sentido de criar clima de hostilidade favorável ao impedimento da presidenta e desgaste das imagens do PT e de Lula. Vale registrar que Sergio Moro publicou, em 2004, um artigo inspirado na operação italiana Mani Pulite, que também investigou corrupção envolvendo empresários e políticos, defendendo o uso da mídia na divulgação de dados de investigações e processos judiciais em curso para influenciar a opinião pública.

Os acontecimentos políticos têm nas figuras de Dilma Rousseff e Luiz Inácio Lula da Silva duas personagens centrais, com diversos inquéritos abertos contra o ex-presidente, atualmente condenado em segunda instância e preso por suposta propriedade de um apartamento tríplex, que teria sido fruto de corrupção. Embora nas próprias sentenças condenatórias não fique provada a propriedade do tríplex por Lula, nem conexões com corrupção relacionada à Petrobras, as condenações foram obtidas a partir, novamente, de decisões que abrem polêmicas entre juristas, jornalistas e amplos setores sociais quanto à sua fundamentação jurídica adequada. Tais acontecimentos, com seus desdobramentos ainda

2 A gravação e divulgação para a imprensa da conversa ocorreu em momento decisivo de tentativa de contornar os problemas políticos enfrentados por Dilma Rousseff, pois a nomeação do ex-presidente Lula para a Casa Civil poderia resultar em negociações que dificultariam a aprovação do impeachment. A nomeação foi suspensa pelo ministro Gilmar Mendes, do STF, sob o argumento de que teria a intenção de criar foro privilegiado para o ex-presidente, constituindo obstrução da justiça. A decisão de Gilmar Mendes foi considerada inconstitucional por diversos juristas e ilustra argumentos a favor da tese de que, não somente o impedimento da presidenta, mas outros acontecimentos são indicativos de golpes institucionais, promovidos pelos poderes Legislativo e Judiciário, com a colaboração da Polícia Federal, não resultando da aplicação adequada de princípios constitucionais e demais instrumentos legais. 
em curso, estão convulsionando o Brasil, colocando em xeque a própria democracia brasileira.

A discussão metodológica nos permitirá melhor situar as condições de disputas de sentido e jogos de poder que envolvem os gestos de narrar jornalisticamente os acontecimentos políticos brasileiros recentes, tendo como referência a noção de golpe, anteriormente delineada.

\section{Percurso metodológico}

As reflexões deste artigo nascem de pesquisas sobre comentários de leitores na internet após narrativas jornalísticas relativas a crimes contra mulheres, captadas no site Uol e no Jornal GGN, on-line, este sob responsabilidade do jornalista Luis Nassif, um dos mais respeitados em atividade no Brasil. A leitura e sistematização dos comentários de leitores, iniciada em fevereiro de 2015, período de efervescência dos acontecimentos políticos envolvendo Dilma Rousseff, Luiz Inácio Lula da Silva e o PT, nos revelou em muitos deles, de cunho favorável às ações de violências físicas e simbólicas contra mulheres, recorrentemente posturas de "acusação" às políticas dos governos Lula e Dilma como responsáveis pela promoção indevida de políticas de empoderamento das mulheres. Os comentários nos levaram a identificar paralelo com as mesmas posições conservadoras e reacionárias, em muitas situações promotoras de violências físicas e simbólicas, que se manifestavam nas opiniões expressas após narrativas de acontecimentos políticos.

Metodologicamente, a busca pelas notícias que narravam acontecimentos relativos a violências contra mulheres nos obrigava à leitura de todas as notícias publicadas ao longo do dia nos sites já referidos. Além dos indícios mais explícitos de temas abordados em uma notícia evidenciados por manchetes e primeiro parágrafo, pesquisas que se preocupam em obter um mapa o mais abrangente possível da temática sob escrutínio precisam se debruçar sobre a integralidade textual, pois elementos temáticos investigados podem estar sugeridos ou citados de forma sumária no corpo do relato, assim como em fotografias e outros recursos visuais. Consequentemente, nossa leitura era a mais abrangente possível, despertando curiosidade acerca das disputas de sentido e jogos de poder em torno da noção do impeachment e de acontecimentos subsequentes como golpe, e não como aplicação legal em estrita observância aos ordenamentos jurídicos brasileiros. Com a abertura de outro foco de investigação, excluímos os comentários de leitores, focando em narrativas jornalísticas identificadas como notícias, editoriais, artigos, entrevistas e demais modalidades textuais informativas, 
opinativas e de análise conjuntural dando conta dos acontecimentos políticos.

A leitura de grande quantidade de narrativas jornalísticas nos dois sites que investigamos neste artigo, assim como de uma diversidade de outros, mostrou-nos duas concepções editoriais em oposição, marcadas, para além de posicionamentos políticos, econômicos, culturais, comportamentais e ideológicos conflitantes, por estratégias narrativas também distintas. Do lado do Jornal GGN e outros editorialmente próximos a ele, a defesa, ainda que muitas vezes com críticas contundentes aos governos e às personas políticas de Dilma Rousseff e de Luiz Inácio Lula da Silva, de que eles promoveram políticas econômicas e sociais que fizeram avançar programas importantes de distribuição de renda, ampliação de direitos à educação, especialmente de ensino superior e técnico, melhoria de atendimento de saúde, além de outras iniciativas que poderiam mitigar as desigualdades sociais brasileiras e os fossos criados por atitudes de exclusão secularmente mantidas. Do lado do Uol e demais mídias identificadas com as estruturas empresariais tradicionais, posições editoriais de negação de qualquer aspecto positivo das políticas dos dois ex-presidentes e do PT, atribuindo-lhes, em adição, responsabilidades por corrupção. Relativamente às estratégias narrativas, o Jornal GGN tende à produção textual mais preocupada com a contextualização dos acontecimentos em curso, evidenciando características das interconexões entre temporalidades e armação da intriga que adiante discutiremos como elementos conceituais. Por sua vez, no Uol prevalecem narrativas produzidas segundo as tradicionais lógicas da factualidade, nas quais as relações temporais são pouco problematizadas ou acionadas, privilegiando-se princípios como o "ouvir os dois lados" e as narrativas focadas no presente dos acontecimentos, sem contextualização.

É importante lembrar que no Brasil há forte concentração na propriedade das mídias, com predomínio de conglomerados familiares, realidade não totalmente modificada com a internet ${ }^{3}$, pois muitos grupos familiares passaram a também atuar na rede, caso do Uol, propriedade do Grupo Folha, controlado pela família Frias de Oliveira. Em que pese tal dado, no entanto, a internet permitiu o surgimento de blogs, sites e outras modalidades midiáticas que se apresentam como alternativas ao modelo ideológico e editorial das 
mídias tradicionais. Relativamente aos sites da nossa pesquisa, o Jornal GGN publica narrativas de equipe própria e reproduz notícias de outras mídias, inclusive das tradicionais. Já o Uol, por fazer parte de conglomerado midiático, publica narrativas produzidas por equipe própria, vindas de agências de notícias, assim como de emissoras de rádio e televisão e de jornais e revistas associados.

Uma última consideração metodológica diz respeito à coleta dos textos jornalísticos que compuseram um corpus de milhares de narrativas, das quais retiramos aqui casos exemplares para ilustrar as disputas de sentido em torno da noção de golpe, a partir dos seguintes acontecimentos:

1) Impeachment de Dilma Rousseff:acontecimentos anteriores à abertura do processo de cassação, durante a tramitação e após sua conclusão. Incluem-se aqui narrativas sobre investigações que indicaram o suposto pagamento de deputados, feitos por empresários, para votarem a favor do processo de impedimento;

2) Processos contra Luiz Inácio Lula da Silva: acontecimentos relativos aos diversos processos abertos contra o ex-presidente, em suas diversas fases, das investigações à condenação e prisão, passando pela condução coercitiva, pela Polícia Federal, com autorização judicial, para prestar depoimento sem que tenha sido anteriormente convocado e se recusado a comparecer.

Pelo grande volume de narrativas, nossa análise da disputa de sentidos e jogos de poder em torno da definição dos acontecimentos políticos, se golpe ou não, será ilustrada por textos que contêm elementos explicadores sobre a polêmica em curso. Nosso movimento metodológico implica reconhecer que os acontecimentos estão em permanente processo de “vir a ser" (QUÉRÉ, 2005; DOSSE, 2013), ou seja, são da ordem hermenêutica, nos dizeres de Louis Quéré (2005), requerendo interpretação sobre o que significam. Dessa condição, assim como da perspectiva de Paul Ricoeur (1994, 1995, 1997) de que simultaneamente sofremos as consequências e agimos sobre e a partir dos acontecimentos, derivamos a noção de que eles estão sob permanentes disputas de sentido e jogos de poder, que se realizam em ações cotidianas que incluem as narrativas, tomadas como parte essencial da ordem hermenêutica do acontecimento. Em suma, o acontecimento está inscrito em uma ampla lógica de afetações, que modernamente inclui a ação das mídias (NORA, 1984, 1993; DOSSE, 2013).

\section{Jornalismo, acontecimento e narrativa}

Passado quase meio século, a proposição de Pierre Nora de que os acontecimentos, a partir de dado momento histórico, se tornaram 
dependentes da mídia, permanece como uma provocação inevitável. Contrariamente a quem pudesse supor que os acontecimentos nessa nova inscrição pudessem ser artificializados, Nora (1984) indica a necessidade de vislumbrá-los a partir de outras condições de ocorrência, que implicam desafios teóricos e metodológicos. Em entrevista posterior à repercussão da sua proposição, o historiador francês declarou:

Parece-me que não existe o pseudo-acontecimento. É o próprio acontecimento que, em relação à História tradicional, mudou de natureza, por causa da transformação operada pelos mass-media. Vivemos doravante um sistema de inflação fenomenológica, como num sistema de inflação monetária. (NORA, 1984, p. 46)

A perspectiva de uma inflação dos acontecimentos pode ser melhor compreendida, a partir do próprio Nora (1993), considerando as reflexões do autor sobre as relações entre memória e história, marcadas por aquilo que ele denomina "aceleração da história".

Para além da metáfora, é preciso ter a noção do que a expressão significa: uma oscilação cada vez mais rápida de um passado definitivamente morto, a percepção global de qualquer coisa como desaparecida - uma ruptura do equilíbrio. (NORA, 1993, p. 7)

Se no que diz respeito ao acontecimento histórico a ruptura do equilíbrio estaria na desproporção provocada pelo poder de sua difusão pela mídia, no tempo e no espaço, é necessário tomar o cuidado de não ir depressa demais às conclusões. É preciso colocar em dúvida a capacidade unilateral da mídia na produção dos acontecimentos, não somente pelos constrangimentos operacionais e editoriais que promovem fraturas em um bloco aparentemente homogêneo, como ainda pelas disputas de sentido e jogos de poder com uma diversidade de outras atrizes e outros atores sociais, na eclosão, desenvolvimento e tentativas de contenção das consequências de um determinado acontecimento ou de um conjunto deles. É o que buscamos evidenciar na contextualização dos acontecimentos políticos brasileiros de que nos ocupamos e aos quais retornaremos.

É inegável, por outro lado, que acontecimentos decisivos nos campos político, cultural, comportamental, econômico e ideológico, sobretudo a partir da segunda metade do século XIX, têm ocorrido em simultâneo à cobertura jornalística, com crescente capacidade da captura da ocorrência no seu momento de eclosão se intensificando na mesma proporção do desenvolvimento tecnológico. Investigar os acontecimentos, a partir dessa perspectiva, traz o desafio de compreender em que medida a eclosão e o desenrolar deles depende de uma "lógica midiática" (HEPP, 2013), considerando 
variáveis como tempo e espaço, atrizes e atores sociais envolvidas/os, como são narrados, que interesses políticos, ideológicos, econômicos, culturais, comportamentais etc. estão em jogo e uma série de outras variáveis.

Em estudos sobre a mídia, com influências vindas de aportes sociológicos, filosóficos e historiográficos - além de outros - o acontecimento adquiriu estatuto heurístico mais recentemente, especialmente focados no jornalismo. Nesses estudos, o acontecimento surge, ora como sinônimo da noção de fato, ora como contraponto à ideia de fato jornalístico e suas implicações para os equívocos da notícia como espelho do real (situadas em preocupações teóricas certamente distintas, são úteis para a compreensão das conexões entre fato, acontecimento e jornalismo, dentre outras, as leituras de Genro Filho, 1987; Mouillaud, 1997; e Sodré, 2009).

No campo da historiografia, como demonstram, dentre outros, Hayden White (1994), Paul Ricoeur (1994) e François Dosse (2013), os acontecimentos nunca são pacíficos, posto que o historiador os reconstitui a partir dos fragmentos deixados por seu passado e essa reconstituição envolve interpretações, muitas delas realizadas a partir de contaminações dos modos culturais, políticos e ideológicos de pensar enraizados no presente de quem pesquisa.
Consequentemente, não é possível pretender que o acontecimento esteja limitado por aquilo que as mídias o fazem ser. Nossa visada sobre os acontecimentos, assim sendo, ao mesmo tempo que os reivindicam como importantes para compreender articulações de sentido atribuídas pelas mídias, solicita o cuidado de não pretender que elas, sozinhas, "constroem" os acontecimentos ou tenham o poder de impor unilateralmente suas interpretações, evitando, assim, os riscos teóricos e metodológicos implicados em certas concepções midiacêntricas, como nos adverte Andreas Hepp (2013).

Ao refletir sobre o jornalismo, Maurice Mouillaud (1997) propõe que os sentidos dos acontecimentos são construídos socialmente, em dinâmica que diz ser à maneira dos estilhaços: no início todo acontecimento é como um corpo estilhaçado, cuja reconstituição se faz a partir dos rumores sociais. Assim, há uma dialética na relação entre mídia e acontecimentos:

Se a mídia não é senhora de acontecimentos que são definidos antes dela, não está pura e simplesmente sujeita a formas nas quais se inscreveria de modo passivo, posto que os "limites" do acontecimento não são unívocos. (MOUILLAUD, 1997, p. 65)

A perspectiva da não univocidade dos sentidos dos acontecimentos nos coloca diante da necessidade de reconhecer que há uma multiplicidade de atrizes e atores sociais que agem 
e sofrem o acontecimento. A origem dos acontecimentos, consequentemente, não é salvaguarda para a sua interpretação, ou para eventual "depuração" do que nele identificaríamos como os traços impostos pelas mídias, pois como propõe Louis Quéré (2005, 2012), há uma dimensão hermenêutica em todo acontecimento que exige colocá-lo sob permanente escrutínio. Em outros termos, uma vez eclodido o acontecimento não cessa de "acontecer", haverá sempre estilhaços capturáveis pelos rumores sociais, nos termos de Maurice Mouillaud, que lhe darão novas significações.

Se há uma natureza do acontecimento talvez ela possa ser melhor definida como a eterna instabilidade de sentidos. Socialmente, acontecimentos importantes estão em contínuo processo de ressignificação, não raro servindo de "justificativa" para ações bastante diversas, como atentados que desencadeiam ações de combate ao terrorismo por parte de governos, mas são também justificados em sua existência como necessários para combater as injustiças impostas por aqueles mesmos governos. Sujeitos às interpretações os acontecimentos, propõe-nos Quéré, se inscrevem na lógica do devir.

Uma vez que o acontecimento é um vir a ser orientado, seu conceito é "teleológico". Devir é, de fato, mudar qualitativamente. Tal mudança implica uma heterogeneidade interna e um movimento direcional: por um lado, não há a mesma coisa de um extremo ao outro do processo; por outro, é impossível perceber um devir se não for apreendida uma transição de um estado para outro, passando por um ou vários estados intermediários. (QUÉRÉ, 2012, p. 26)

A noção do acontecimento como devir progride, em Louis Quéré, da sua proposição da exigência de interpretação anunciada no texto "Entre facto e sentido: a dualidade do acontecimento", de 2005, em que a natureza hermenêutica é destacada como central nos processos de compreensão dos acontecimentos. Seguindo a fórmula tomada de empréstimo a Herbert Mead, de que o acontecimento é aquilo que ele vier a ser, Quéré chama a atenção para a natureza de eterna incompletude dos sentidos de um determinado acontecimento, sempre sujeito a diversos inquéritos.

O devir do acontecimento só faz sentido à medida que é narrado - o que constitui parte do seu vir a ser - estando na sua narração talvez a parte mais sensível para a compreensão das disputas de sentido em torno dele e da heterogeneidade que o compõe. Com a necessária ressalva de que a narrativa não substitui a ação do homem sobre o mundo e seus acontecimentos, no sentido de que narrar não corresponde à possibilidade de abarcar a totalidade do que é alvo da narrativa, mas reconhecendo que a narrativa é ela própria uma forma de ação sobre os acontecimentos, o percurso teórico relativo às 
imbricações entre acontecimento e narrativa pode evitar alguns equívocos. Ainda é fundamental não pretender que a narrativa corresponda à experiência do que é narrado ou que o gesto narrativo possa dar conta de mitigar sofrimentos. Por outro lado, reconhece-se que narrar um acontecimento é uma estratégia eficiente de denunciar injustiças, de lutar pelo reconhecimento da justeza de uma causa, pois narramos potencialmente para uma coletividade que pode sensibilizar-se e juntar forças. Nesse sentido, narramos para dar conta de ampliar nossas experiências e ações sobre o mundo e como estratégia para fazer valer nossos pontos de vista e nossas reivindicações, o que constitui parte essencial das disputas de sentido e dos jogos de poder implicados nos acontecimentos.

Consequentemente, narramos um acontecimento como uma das estratégias de enfrentá-lo, como parte da dialética agir-sofrer: eu sofro e ajo sobre e a partir de um determinado acontecimento e isso tanto no que diz respeito aos acontecimentos que me afetariam mais isoladamente - caso dos eventos que me requerem um tratamento psicanalítico para sua compreensão, superação ou convívio e àqueles que me afetam e simultaneamente a uma comunidade, como os acontecimentos políticos brasileiros aqui investigados, cujos desenlaces e possíveis interpretações mal começam a ser delineados. A dialética agir-sofrer implica que o acontecimento age sobre mim e sobre o social, e de retorno agimos sobre ele, em processo que pode nunca cessar.

A instabilidade do acontecimento, o seu eterno devir, nos parece indicar uma profícua dialética acontecer-narrar, cuja compreensão se inicia pelas reflexões de Paul Ricoeur acerca da intriga e suas diversas modalidades de mediações. Segundo o autor, a intriga

\begin{abstract}
Primeiro, faz mediação entre acontecimentos ou incidentes individuais e uma história considerada como um todo. Quanto a isso, pode-se dizer equivalentemente que ela extrai uma história sensata de - uma pluralidade de acontecimentos ou de incidentes (os pragmata de Aristóteles); ou que transforma os acontecimentos ou incidentes em - uma história. As duas relações reciprocáveis expressas pelo de e pelo em caracterizam a intriga como mediação entre acontecimentos e história narrada. Em consequência, um acontecimento deve ser mais do que uma ocorrência singular. Ele recebe sua definição de sua contribuição para o desenvolvimento da intriga. (RICOEUR, 1994, p. 103 , grifo do autor)
\end{abstract}

Em um primeiro momento, estamos diante da necessidade de compreensão da ação da intriga para a composição narrativa, segundo a lógica ricoeuriana de que narrar é agenciar acontecimentos diversos, é a "síntese do heterogêneo". Do ponto de vista jornalístico está em jogo o agenciamento dos estilhaços aos quais refere 
Maurice Mouillaud, permitindo que o acontecimento alcance, pela narrativa, inteligibilidade e legibilidade, não se esquecendo que esse procedimento está longe de pacificar os sentidos do acontecimento. Pelo contrário, vai situá-lo inevitavelmente no terreno bastante pantanoso das interpretações e disputas de sentido, tal como investigamos em outrolugar (CARVALHO, 2012). A armação da intriga, no entanto, não esgota, segundo a visada de Paul Ricoeur, os desafios para a compreensão da narrativa, que o autor situa, a partir de Santo Agostinho e de Aristóteles, no intrincado jogo das temporalidades e da construção textual.

Partindo da aporia do tempo agostiniana, Ricoeur (1994) ressalta que, uma vez sendo impossível definir com precisão o que é o tempo, tarefa complexa também para a filosofia e a física, a narrativa surge como a possibilidade de tornar o tempo humano e, ao final, seria ela guardiã do tempo: pela narrativa passado, presente e futuro podem se distinguir, mas também somos levados a reconhecer a fusão entre eles, por exemplo, quando do presente olhamos para o passado e vislumbramos o futuro. Assim, as relações temporais na narrativa são da ordem de uma tentativa de humanização do tempo e os acontecimentos narrados se inscrevem na urgência de compreensão do que eles significam para além das aparências do seu "momento inaugural". Em outros termos, se aprisionado a um tempo único, o do passado, o acontecimento teria uma autonomia avassaladora sobre nós, impedindo-nos sua compreensão e negando o devir de que nos fala Louis Quéré.

Outra condição das narrativas é importante para compreendermos as interconexões com os acontecimentos, especialmente com a perspectiva do seu eterno devir. Ricoeur (1994) nos diz que toda narrativa se inscreve no movimento da tríplice mimese, entendendo o processo mimético não como a imitação, seja ela do real ou de qualquer outra instância, mas como a ação mesma de tecer uma intriga. A tríplice mimese nos diz que toda narrativa surge de um mundo prefigurado (mimese I), portanto, ela se inscreve em um passado, mas também em determinadas condições éticas, morais e culturais que lhe precedem. $\mathrm{O}$ ato de configurar a narrativa (mimese II) constitui o momento de construção textual efetiva, com o agenciamento dos acontecimentos discordantes, como a "síntese do heterogêneo", com o acionamento de personagens, enfim, de cumprimento de todas as condições necessárias para que uma narrativa emerja. A mimese II é a mediadora entre o mundo prefigurado (mimese I) e o ato de leitura, que constitui a mimese III, acionadora não somente dos sentidos propostos pelo que nos oferece a mimese II, mas momento de intervenção criadora do leitor, que atribuirá novos sentidos ao que foi narrado. 
Em função do circuito mimético virtuoso é que nos parece ser possível indicar com maior precisão as imbricações entre acontecimento e narrativa. Se uma primeira interconexão está no fato de narrativas nos contarem sobre acontecimentos históricos, ficcionais e de outras ordens, a segunda nos aponta para a perspectiva do eterno devir: todo acontecimento está no mundo sujeito às mais diversas interpretações, segundo a lógica agir-sofrer. Condições éticas, morais, culturais, econômicas, comportamentais e ideológicas não podem ser esquecidas quando das análises das interconexões acontecimento-narrativa, pois nos parece que são elas as motivadoras das disputas de sentido. Desse modo, não somente no interior de uma determinada realidade com seus valores, mas também externamente a ela, os acontecimentos poderão adquirir feições distintas, conflitantes, servindo de mote para ações que podem se situar uma na contramão da outra, como exploraremos na sequência, na análise de narrativas sobre os acontecimentos políticos brasileiros recentes publicadas por mídias situadas em campos interpretativos e linhas editoriais distintos.

Não desconhecemos as discussões sobre narrativas jornalísticas feitas por autoras e autores brasileiros a partir das contribuições de Paul Ricoeur, com suas potencialidades e limites, tendo delas nos valido (CARVALHO, 2012).
No entanto, no escopo deste artigo, inclusive pelos limites de espaços disponíveis, privilegiamos efetivamente as relações entre acontecimento e narrativa em suas perspectivas gerais. São elas que nos guiam para a análise das materialidades jornalísticas de que nos ocupamos na sequência.

\section{Disputas de sentido em torno da noção de golpe}

Em texto de análise sobre o cenário político antes do impeachment, o jornalista Luis Nassif investiga o papel de atores sociais do governo Dilma Rousseff, indicando inapetência para enfrentar os riscos do impedimento, especialmente pela ação pouco eficaz do então ministro da Justiça, José Eduardo Cardoso. O texto foca ainda em ações de ministros do Superior Tribunal Eleitoral, do Tribunal de Contas da União e do Supremo Tribunal Federal, avaliando que todas essas instâncias estariam tomando decisões questionáveis do ponto de vista da estrita observância das leis. Além disso, são nomeados os riscos da Operação Lava Jato para a desestabilização política e econômica. Publicada em outubro de 2015, a narrativa "A interminável armação do golpe do impeachment" começa delineando o cenário político:

Há duas posturas contrárias ao impeachment de Dilma Roussefff: um pequeno grupo dos que aprovam o governo em qualquer hipótese; e o grupo dos que, mesmo sendo críticos em relação a ele, encaram o 
impeachment como golpe contra a democracia. De fato, significaria tirar do país o único grande diferencial positivo em relação aos demais emergentes: uma democracia que se acredita consolidada. (NASSIF, 2015, on-line)

Essa narrativa aponta as disputas semânticas relativamente à noção dos acontecimentos como golpe, ainda no início das movimentações em torno do impeachment, inclusive com a saída às ruas de milhões de pessoas favoráveis à destituição de Dilma Rousseff. Vencer essa disputa significaria mais do que atribuir um qualificativo aos acontecimentos em curso. Seguindo as pistas que delineamos anteriormente como pertinentes às interconexões entre acontecimentos e narrativas, vislumbramos as dimensões do vir a ser, da natureza teleológica dos acontecimentos e das dimensões temporais da narrativa, assim como da sua potencialidade de, pela atribuição de sentidos, auxiliar na moldagem e/ou remodelagem de um determinado acontecimento.

Após a admissibilidade do pedido de impeachment, o Jornal GGN publicou notícia sobre a instauração do Tribunal Internacional pela Democracia, composto por nove especialistas em direitos humanos, para julgamento da legalidade do processo. Sem existência formal, tratou-se de tribunal simbólico, que informa a narrativa sob título "Impeachment de Dilma é golpe de Estado, decide Tribunal
Internacional", indicou por unanimidade não haver sustentação constitucional para admissibilidade do processo.

No Brasil, disseram os jurados, "o golpe está assentado não só na decisão parlamentar, mas também na legitimação que essa decisão política obteve no Poder Judiciário, que não enfrenta questões de fundo importantes, como a ocorrência ou não do crime de responsabilidade ou a violação de princípios constitucionais relacionados ao contraditório, à ampla defesa e à fundamentação das decisões". 0 papel da mídia também não foi esquecido na sentença: " 0 golpe pode ser visto no reforço da agressiva desconstrução efetuada pelos meios de comunicação de massa da própria pessoa da presidenta, demonstrando - por vezes de modo disfarçado, por vezes notório - um preconceito machista". (THUSWOHL, 2016, on-line)

A natureza machista e misógina do processo de impeachment aparece em uma série de outras narrativas do Jornal GGN nas quais a tese do golpe é sustentada, assim como são destacadas ações das mídias e do Poder Judiciário.

Do Uol também retiramos duas narrativas sobre o processo de impeachment de Dilma Rousseff. A primeira, publicada em abril de 2016, portanto antes da votação final do impedimento, sob o título "O que há de comum entre o golpe de 1964, o impeachment de Collor e hoje?", traça paralelos jurídicos e políticos entre o golpe civil-militar 
que derrubou João Goulart da presidência, em 1964, o impeachment de Fernando Collor, presidente brasileiro afastado do poder por este instrumento, e o processo contra Dilma Rousseff. O texto traz, dentre outros dados comparativos, denúncias de corrupção, índice de aceitação pela opinião pública, situação política e econômica do Brasil, apoio vindo da mídia e pressões militares como determinantes para o futuro dos três presidentes listados. $\mathrm{Na}$ abertura, temos que:

Uma das principais discussões sobre o processo de impeachment contra a presidente Dilma Rousseff refere-se a um termo: golpe. Em 1964 a palavra foi usada quando João Goulart foi retirado do comando do país. Há quem defenda que o que acontece hoje não é uma ação golpista, mas o legítimo processo de impeachment, tal qual o que Fernando Collor recebeu em 1992. (LOPES, 2016, on-line)

A narrativa ouve especialistas em direito e cientistas políticos, com alguns afirmando a legalidade do processo e outros apontando a possibilidade de interpretação como golpe. No entanto, na abertura do texto, explicita-se a chave de leitura pretendida pela narrativa, ao afirmar que "há quem defenda que o que acontece hoje não é uma ação golpista, mas o legítimo processo de impeachment, tal qual o que Fernando Collor recebeu em 1992". Essa chave de leitura proposta pelo autor da notícia sugere a inadequação da utilização do conceito de golpe como passível de aplicação às características condutoras do pedido de afastamento de Dilma Rousseff.

A segunda narrativa que escolhemos do Uol tem como título "Foi impeachment ou golpe? Veja a opinião de quem foi a protestos em SP e RJ" e foi publicada no dia 31 de agosto, logo após a decisão do Senado que aprovou em definitivo o impeachment de Dilma Rousseff. São entrevistadas cinco pessoas favoráveis e cinco contrárias ao impeachment, todas fotografadas para ilustrar o texto, cuja abertura informa que:

\begin{abstract}
A quarta-feira (31) começou com muita expectativa, teve muita tensão à tarde e terminou com manifestações e violência. 0 dia do impeachment da agora ex-presidente Dilma Rousseff (PT) foi o auge de período conturbado, marcado, entre outras coisas, pela divisão entre apoiadores da ex-presidente Dilma Rousseff e os que defendiam a sua saída do cargo. (UOL, 2016, on-line)
\end{abstract}

Assim como na narrativa anterior, o Uol explicita a disputa de sentidos em torno da noção de golpe, adotando o princípio de ouvir os lados conflitantes da disputa, na tentativa de fazer parecer que os textos não sustentam pontos de vista favoráveis a uma atriz ou a um ator social da querela. Como vimos no primeiro texto do site que analisamos, no entanto, as sugestões de "tomada de partido" se dão por meio de estratégias narrativas que não se limitam à suposta neutralidade técnica 
propiciada pelas vozes discordantes distribuídas em uma mesma narrativa.

Esses quatro textos ilustram as disputas de sentido que se dão, especialmente no campo das narrativas, em torno da noção de golpe. Embora haja, nos dois sites, narrativas que defendam os dois pontos de vista conflitantes, golpe ou processo em estrita observância aos preceitos constitucionais, é importante destacar que o Uol, representante das mídias tradicionais, somente entra na polêmica quando setores sociais contrários ao impeachment conseguem, efetivamente, colocar em dúvida a lisura do processo contra Dilma Rousseff precisamente pelas narrativas que atribuem ao acontecimento a ideia de golpe. Estão em jogo, consequentemente, visões de mundo que, ao conflitarem, deixam entrever posições políticas, econômicas, ideológicas, comportamentais, culturais, e outras, que opõem as mídias tradicionais a propostas que se oferecem como alternativas aos modelos jornalísticos vigentes.

Por seu turno, os processos judiciais envolvendo o ex-presidente Luiz Inácio Lula da Silva recebem, em diversas narrativas do Jornal GGN, abordagens indicando tratar-se da continuidade de um procedimento de golpe contra a democracia brasileira, iniciado com o impeachment de Dilma Rousseff. Reforça essa tese o fato de as condenações e prisão
- já ocorridas - poderem retirá-lo da disputa eleitoral de 2018, para a qual desponta, em pesquisas de intenções de voto, como à frente de todos os demais concorrentes. Dois meses após a prisão, Luiz Inácio Lula da Silva aparece, em pesquisa realizada pelo Instituto Datafolha, como o candidato preferido de $30 \%$ dos eleitores, em primeiro turno. Nas simulações de segundo turno, venceria todos os concorrentes (BALTHAZAR, 2018).

A primeira narrativa sobre o ex-presidente tem como título "Perseguição de Lula é outra fase do golpe', diz Dilma ao Página12” e reproduz entrevista que Dilma Rousseff concedeu ao jornal Página 12, da Argentina:

Bem ... 0 que está em andamento agora
é impedir a candidatura de Lula, que seria
invencível para eles. Outra é a consoli-
dação da regressão que será herdada do
golpe, como o congelamento de vinte anos
de gastos públicos aprovados como uma
reforma constitucional logo após o impea-
chment. (ROUSSEFF, MILENA, PIGNOTTI,
2018, on-line) É significativo que a narrativa sobre a continuidade do golpe seja defendida pela que seria sua primeira vítima, Dilma Rousseff, que argumenta indicando tratar-se de golpe mais amplo, contra a democracia brasileira e quem representa pensamentos políticos à esquerda, mas não somente no Brasil. Assim, ela lembra de processos contra os ex-presidentes da 
Argentina, Cristina Kirchner, e do Paraguai, Fernando Lugo. Dilma Rousseff destaca ainda que os acontecimentos políticos brasileiros em curso deixam ver interesses de grupos financeiros especulativos, que concentram riquezas e agravam a concentração de renda, aumentando as desigualdades econômicas.

A segunda narrativa do Jornal GGN informa sobre a realização de seminário, promovido pelo Instituto Lawfare, que discutirá a sentença de condenação do ex-presidente Lula em segunda instância. O texto, que tem como título "Instituto Lawfare realiza hoje debate sobre Caso Lula na ONU", informa que "o termo 'lawfare'se refere à utilização das normas legais e de procedimentos jurídicos para fins políticos”. O seminário, segundo a narrativa, contou como convidado especial "o advogado australiano Geoffrey Robertson, que fez duras críticas ao julgamento do ex-presidente feito pelo TRF4" (NASSIF, 2018, on-line). Geoffrey Robertson representa Lula em processo apresentado à comissão de Direitos Humanos da ONU, com denúncia de prática de lawfare, cerceamento à ampla defesa e outras irregularidades jurídicas cometidas contra Lula em todas as fases do julgamento, incluindo condução coercitiva injustificada.

A primeira narrativa sobre os processos contra Lula que destacamos do Uol tem por título "Análise: TRF mostrou que tríplex era de Lula, mas corrupção não ficou clara", na qual são ouvidos dois especialistas em direito. A tônica das análises recai sobre os argumentos dos desembargadores que condenaram o ex-presidente por unanimidade, destacando a relação com suposta corrupção da Petrobras, ponto que os analistas consideraram frágil nas argumentações de condenação. Segundo o texto, "em seu julgamento, os desembargadores entenderam que causou um agravante o fato de Lula, à época dos crimes, estar em posição de alto poder e influência, a Presidência da República" (FUjITA, 2018, on-line).

Sob o título "Para cientista político, condenação dificulta 'vitimização' de Lula”, a segunda narrativa do Uol é construída a partir de entrevista com o cientista político José Álvaro Moisés, da Universidade de São Paulo. A condenação por unanimidade, em transmissão ao vivo por canais de televisão e internet e os argumentos dos desembargadores são alguns dos fatores que levam à avaliação do professor, relativamente ao processo eleitoral de 2018 , de que tais fatos " [...] enfraquece a situação eleitoral de Lula e ao mesmo tempo introduz uma tensão na disputa". O texto ainda destaca que:

Lula tem repetido, como estratégia de defesa, que é vítima das elites brasileiras, que tentariam, via abuso da Justiça, barrar sua nova intenção de concorrer à Presidência. 0 petista é 0 líder das intenções de voto, com cerca de $30 \%$, segundo a pesquisa 
Datafolha divulgada em dezembro último. (AZEVEDO, 2018, on-line)

Assim como nas narrativas sobre o impeachment de Dilma Rousseff, as disputas de sentido envolvendo a noção de golpe estão presentes nas narrativas dos dois sites sobre os processos judiciais contra Lula, e mais uma vez posições antagônicas deixam perceber disputas que extrapolam políticas editoriais. Estão em jogo novos modos de praticar o jornalismo, com as possibilidades abertas pela internet, indicando que, sem negar a inflação dos acontecimentos que Pierre Nora identifica como própria da era das mídias, as disputas de sentido e jogos de poder envolvidos na definição e apropriação dos acontecimentos tem em dois modelos jornalísticos antagônicos dois atores sociais de relevo, em concorrência com outras atrizes e outros atores sociais.

\section{Considerações finais}

As disputas de sentido e jogos de poder que envolvem a interpretação dos acontecimentos políticos brasileiros recentes, que aqui ilustramos com o impeachment de Dilma Rousseff e os processos judiciais que resultaram na condenação e prisão de Luiz Inácio Lula da Silva, com repercussões para o PT, indicam interconexões entre mídias jornalísticas e acontecimentos que se tornaram mais complexas desde as reflexões seminais de Pierre Nora. Nos dois casos analisados, a participação dos atores jornalísticos tradicionais deve ser pensada a partir da fusão de interesses com partes dos poderes policiais e judiciários, colocando em xeque as suposições de que o jornalismo deveria agir como fiscalizador desses e de outros poderes, denunciando excessos ou desvios.

Acrescenta-se à equação o fato de as próprias disputas entre modelos jornalísticos não se restringir à concorrência por mercado, opondo os dois sites investigados em função de variáveis como posições políticas e ideológicas divergentes e visões jornalísticas centradas em perspectivas mecânicas de ouvir os dois lados em disputa (Uol) ou fazer da análise de conjuntura e das circunstâncias históricas condições para compreensão do que está em jogo, para além da natureza censitária das posições em conflito (Jornal GGN). Em termos das conexões entre tessitura da intriga e temporalidades, o Jornal GGN produz narrativas nas quais os acontecimentos são perspectivados para além da factualidade, implicando dimensões de passado, presente, futuro e memória que permitem vislumbrar os diversos agentes e consequências dos eventos sob óticas mais complexas do que o mero desenrolar de eventos que se sucedem cotidianamente.

O olhar sobre os acontecimentos e as narrativas pela perspectiva das imbricações entre ambos nos sugere que as mídias podem ser 
melhor compreendidas em suas estratégias textuais e em suas negociações de sentido com as/os demais atrizes e atores sociais quando desse cotejamento. Além disso, os modos como as mídias jornalísticas interpretam narrativamente os acontecimentos são no mínimo indicativos dos papeis que elas se auto atribuem. Nos acontecimentos políticos brasileiros recentes, como buscamos evidenciar, há entre as mídias tradicionais e aquelas que se apresentam como alternativa editorial àquelas, disputas que vão além dos sentidos atribuídos aos acontecimentos, posto que podem nos revelar modos particulares de interação e/ou oposição a outras atrizes e a outros atores sociais.

Mas é também fundamental recuperar as contribuições de Paul Ricoeur acerca da dialética agir-sofrer o acontecimento, e de Louis Quéré sobre a natureza de devir dos acontecimentos, para compreendermos que também está em cena uma diversidade de atrizes e de atores sociais. No cenário político brasileiro atual, setores da Polícia Federal, do Poder Judiciário e do Ministério Público, em consonância com as mídias tradicionais, e por isso mesmo muito criticados por aquelas que se apresentam como novas mídias, agem de todas as formas possíveis na tentativa de cercar os transbordamentos de sentido e os efeitos concretos dos acontecimentos. Essas ações tanto têm sido interpretadas como ameaça à democracia brasileira, quanto indicativa dos limites do poder das mídias, assim como de qualquer outro ator social, de exercer controle absoluto sobre os acontecimentos, uma vez que estes eclodem ou são intencionalmente propostos. De qualquer modo, e com a talvez impossibilidade de corretamente interpretar acontecimentos ainda em curso, as tentativas de controle dos transbordamentos de sentido dos acontecimentos são indicativas de ameaças de ruptura dos padrões tradicionais de atuação das mídias jornalísticas, como também de atrizes e de atores políticos, policiais e dos poderes judiciais. O acontecimento, por exigir ação e interpretação, costuma erodir muito do que encontra à sua volta.

Metodologicamente, nosso empreendimento analítico apontou para algumas dificuldades, todas elas derivadas do desafio de investigar acontecimentos recentes ou ainda em curso. Merecem atenção em investigações futuras as relações mais intricadas entre propriedades das mídias jornalísticas e os posicionamentos por elas assumidos face a acontecimentos nos quais são também parte interessada, verificando mais detidamente interesses políticos, econômicos, ideológicos e outras variáveis. Do mesmo modo não pudemos, por questão de escopo e de espaço, alargar as discussões teóricas acerca das relações entre narrativa e acontecimento, incorporando literaturas brasileiras recentes que trataram desses 
entrelaçamentos. De qualquer modo, nossa intenção foi chamar atenção para a natureza nada pacificada dos acontecimentos, especialmente os políticos, o que traz à tona uma miríade de atrizes e atores e sociais que, pela narrativa e pelas demais ações cotidianas, travam batalhas em torno dos sentidos dos acontecimentos, deixando a ver jogos de poder que têm nas mídias jornalísticas agentes que não podem ser negligenciados, particularmente quando em ações orquestradas com outras/os atrizes e atores sociais, a exemplo, nos casos analisados, de setores do Judiciário e da Polícia Federal.

Desse modo, nossa perspectiva das disputas de sentido e dos jogos de poder como elementos essenciais para a compreensão das estratégias textuais jornalísticas é tributária da observação dos complexos imbricamentos entre acontecimentos e narrativas e devem considerar ao menos três variáveis teóricas e metodológicas: 1) os acontecimentos, uma vez eclodidos, por dinâmicas naturais ou provocados por ações humanas diversas, não podem ser contidos em seus transbordamentos de sentidos, dada a sua natureza de eterno devir. Como consequência, estão inscritos, segundo Louis Quéré, em uma lógica hermenêutica, exigindo interpretações e inquéritos sucessivos, por meio dos quais atrizes e atores sociais conflitantes proporão novos sentidos aos acontecimentos, que deixam de pertencer exclusivamente ao passado, inquietando o presente e demandando ações para o futuro; 2) as narrativas não podem ser limitadas em sua compreensão a lógicas textuais formais ou estruturais, mas devem, na esteira das reflexões de Paul Ricoeur, serem estudadas também em função das relações entre tessitura da intriga e temporalidades. Se entendemos as narrativas como síntese do heterogêneo, como discordância concordante ou concordância discordante, estamos diante de personagens e acontecimentos dispersos no tempo e no espaço, acionando relações complexas entre passado, presente e futuro que somente adquirem inteligibilidade em função das estratégias narrativas. E o mais importante, o escrutínio das narrativas deve estar atento a quais são as personagens e acontecimentos articulados, com suas idiossincrasias, contradições e posições que permitem vislumbrar os sentidos em disputa, as interpretações do mundo social em jogo; 3) como acontecimentos e narrativas possuem em comum complexas relações com as temporalidades, são estas ponto de partida indispensável em investigações que os têm como foco. Mas também, como buscamos evidenciar, as narrativas constituem estratégias privilegiadas na atribuição de sentidos aos acontecimentos, sendo delas que nos valemos quando da proposição de novas interpretações, como se verificou na querela entre impedimento segundo preceitos legais 
da presidenta Dilma Rousseff, ou golpe, precisamente porque aqueles preceitos não teriam sido observados.

\section{Referências}

AZEVEDO, Guilherme. Para cientista político, condenação dificulta "vitimização" de Lula. 2018. Disponível em: $<$ https://eleicoes.uol. com.br/2018/noticias/2018/01/24/ficou-maisdificil-de-lula-se-colocar-como-vitima-dizanalista-politico.htm>. Acesso em: 24 jan. 2018.

BALTHAZAR, Ricardo. Com ausência de Lula, Bolsonaro e Marina lideram Datafolha: com apoiadores de Lula sem alternativa, disputa eleitoral segue indefinida. Disponível em:<https://www1.folha.uol.com.br/ poder/2018/04/prisao-enfraquece-lula-e-poemarina-perto-de-bolsonaro-diz-datafolha. shtml>. Acesso em: 17 jun. 2018.

CARVALHO, Carlos Alberto de. Jornalismo, homofobia e relações de gênero. Curitiba: Appris, 2012.

\section{DOSSE, François. Renascimento do} acontecimento: um desafio para o historiador: entre Esfinge e Fênix. São Paulo: Editora Unesp, 2013.

FUJITA, Gabriela. Análise: TRF mostrou que tríplex era de Lula, mas corrupção não ficou clara. 2018. Disponível em: $<$ https://eleicoes. uol.com.br/2018/noticias/2018/01/25/analiseato-de-corrupcao-de-lula-em-contratosda-oas-nao-ficou-claro.htm>. Acesso em: 25 jan. 2018.

GENRO FILHO, Adelmo. 0 segredo da pirâmide: para uma teoria marxista do jornalismo. Porto Alegre: Tchê!, 1987
HEPP, Andreas. Cultures of mediatization. Cambridge: Polity Press, 2013.

LOPES, Nathan.0 que há de comum entre o golpe de 1964, o impeachment de Collor e hoje? 2016. Disponível em: <https:// noticias.uol.com.br/politica/ultimasnoticias/2016/04/17/o-que-ha-em-comumentre-o-golpe-de-1964-o-impeachment-decollor-e-hoje.htm>. Acesso em: 17 abr. 2016.

MORO, Sérgio Fernando. Considerações sobre a operação mani pulite. Revista CEJ, Brasília, n. 26, p. 56-62, jul./set. 2004. Disponível em: <http://media.folha.uol.com. br/poder/2015/12/29/trabalho_internet_revista. pdf>. Acesso em: 20 set. 2017.

NASSIF, Lourdes. Instituto Lawfare realiza hoje debate sobre Caso Lula na ONU. 2018. Disponível em: <https://jornalggn.com.br/ noticia/instituto-lawfare-realiza-hojedebate-sobre-caso-lula-na-onu>. Acesso em: 29 jan. 2018.

MOUILLAUD, Maurice. A crítica do acontecimento ou o fato em questão. In: MOUILLAUD, Maurice; PORTO, Sérgio Dayrell (Org.). 0 jornal da forma ao sentido. Brasília: Paralelo 15, 1997.

NASSIF, Luis. A interminável armação do golpe do impeachment. 2015. Disponível em: <https://jornalggn.com.br/noticia/ainterminavel-armacao-do-golpe-doimpeachment>. Acesso em: 07 out. 2015.

NORA, Pierre. Entre memória e história: a problemática dos lugares. Projeto História, n. 10, 1993, p. 7-28. Disponível em: <https:// revistas.pucsp.br/index.php/revph/article/ viewFile/12101/8763>. Acesso em 06 jan. 2016. 
. O acontecimento e o historiador do presente. In: NORA, Pierre et al. A nova história. Lisboa: Edições 70, 1984. p. 45-56. QUÉRÉ, Louis. Entre o facto e sentido: a dualidade do acontecimento. Trajectos Revista de comunicação, cultura e educação, Lisboa, n. 6, 2005. . A dupla vida do acontecimento: por um realismo pragmatista. In: França, Vera Regina Veiga; Oliveira, Luciana (Org.) Acontecimentos: reverberações. Belo Horizonte: Autêntica Editora, 2012. RICOEUR, Paul.Tempo e narrativa. Campinas: Papirus, 1994. Tomo I.

.Tempo e narrativa. Campinas: Papirus, 1995. Tomo II.

.Tempo e narrativa. Campinas: Papirus, 1997. Tomo III.

ROUSSEFF, Dilma, MILENA, Lilian, PIGNOTTI, Dario. Perseguição de Lula é outra fase do golpe, diz Dilma ao Página12. 2018. Disponível em: <https://jornalggn.com.br/ noticia/perseguicao-de-lula-e-outra-fase-dogolpe-diz-dilma-ao-pagina12>. Acesso em: 21 jan. 2018.

SODRÉ, Muniz. A narração do fato: notas para uma teoria do acontecimento. Petrópolis: Vozes, 2009.

THUSWOHL, Maurício. Impeachment de Dilma é golpe de Estado, decide Tribunal Internacional. 2016. Disponível em: <https:// jornalggn.com.br/noticia/impeachment-dedilma-e-golpe-de-estado-decide-tribunalinternacional>. Acesso em: 21 jul. 2016.

UOL. Foi impeachment ou golpe? Veja a opinião de quem foi a protestos em SP e RJ.
2016. Disponível em: <https://noticias.uol.com. $\mathrm{br} /$ politica/ultimas-noticias/2016/08/31/foiimpeachment-ou-golpe-veja-opiniao-de-quefoi-a-protestos-em-sp-e-no-rj.htm>. Acesso em:31 ago. 2018.

WHITE, Hayden. Trópicos do discurso: ensaios sobre a crítica da cultura. São Paulo: Edusp, 1994.

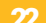




\section{Narratives about the coup in Brazil: event, journalism and disputes of meaning}

\section{Abstract}

From recent Brazilian political events - the impeachment of Dilma Rousseff and the judicial processes that led to the conviction and arrest of former President Luiz Inácio Lula da Silva - we reflected about disputes of meaning and power plays that involve the gestures of narration journalistically the events. Methodologically, we analyze news collected from the Uol and GGN News sites, adopting as a procedure possible inter-relationships between narratives and events. From the analysis, emerge disputes of meaning in the definition of political events that oppose the notion of a coup against democracy to that of political and judicial actions guided by constitutional principles.

\section{Keywords}

Journalism. Event. Narrative.

\section{Narrativas sobre el golpe en Brasil: acontecimiento, periodismo y disputas de sentido}

\section{Resumen}

En el marco de los recientes acontecimientos políticos brasileños - el impeachment de Dilma Rousseff y los procesos judiciales que llevaron a la condena y a la detención del ex presidente Luiz Inácio Lula da Silva reflejamos sobre las disputas de sentido y los juegos de poder que envuelven los gestos de narrar periodísticamente los acontecimientos. Metodológicamente, analizamos noticias recogidas de los sitios Uol y Jornal GGN, adoptando como procedimiento entrecruzamientos posibles entre narrativas y acontecimientos. Del análisis emergen disputas de sentido en la definición de los acontecimientos políticos que contraponen la noción de golpe contra la democracia a la de acciones políticas y judiciales pautadas por principios constitucionales.

\section{Palabras clave}

Periodismo. Acontecimientos. Narrativa.

\section{Carlos Alberto de Carvalho}

Doutor em Comunicação pelo Programa de Pós-Graduação em Comunicação Social da Universidade Federal de Minas - UFMG. Professor Associado do Curso de Comunicação Social e do Programa de Pós-graduação em Comunicação Social da Universidade Federal de Minas Gerais - UFMG, Belo Horizonte, Minas Gerais, Brasil. E-mail:carloscarvalho0209@gmail.com Orcid: https://orcid.org/0000-0001-8433-8794
As pesquisas que permitiram a produção deste artigo são financiadas pela Fundação de Amparo à Pesquisa de Minas Gerais (Fapemig), pelo Conselho Nacional de Desenvolvimento Científico e Tecnológico (CNPq) e pela Coordenação de Aperfeiçoamento de Pessoal de Nível Superior (Capes). 